\title{
Intrafirm labour mobility as element of corporate social responsibility
}

\author{
Alexandr Kokovkihin \\ Ural State University of Economics \\ Yekaterinburg, Russia, \\ gov66@inbox.ru
}

\author{
Ivan Borisov \\ Ural State University of Economics \\ Yekaterinburg, Russia, \\ borisovivan2006@yandex.ru
}

\author{
Elmira Gatina \\ Metal Group Capital Ltd. \\ Chelyabinsk, Russia, \\ egatinie@gmail.com
}

\begin{abstract}
This article aims to analyze corporate promotion practice of different worker categories taking into consideration their level of education, work experience and firm-specific capital. The analysis is based on the model of career theory $\sigma$ proposed by one of its founders - Lorne Carmichael. The basic model was expanded due to taking into account cofactors, having potential impact on the intensity of vertical mobility and salary growth, including personal characteristics of employees. The expanded model has been empirically tested using the authors' micro data on the employees of the Russian industrial enterprise. The main result is that individual characteristics such as gender, marital status, age can influence career prospects, as well as traditional factors such as education, working experience, tenure, etc. The article may be interesting for researchers specializing in Labor economics, corporate and social responsibility and human research management. Results of the research are useful for elaborating personnel promotion policy and identifying career paths.
\end{abstract}

Keywords - theory of human capital, career management, personnel policy, internal labour market, firm-specific assets

\section{INTRODUCTION}

One of the essential characteristics of stably developing economies is the level of corporate social responsibility (CSR). This conception implies following the interests of the society and the responsibility of a firm for the influence of its activity exerted on the societal parties concerned. Regarding the field of human resources management, the program of CSR should be directed towards recruiting and retaining personnel. Such corporate policy concerns potential workers among university-graduated students, as well as current company workers; both of these groups perceive loyalty as a company loyalty through the salary payment system, social protection and career growth.

Increasing involvement of the most well-known Russian companies into the system of the international division of labour and the development of their internal processes to meet CSR standards stimulates organizations to incorporate foreign best practices of personnel management. Thereupon, the theory of career development in terms of the Personnel Economics conception [1] became the basis for working out the methods and instruments of staff's career management. At the same time, the managerial practice of Russian companies reserved a series of formal and informal norms of personnel decision-making, which are typical for the administrativecommand system.

The design of an effective personnel policy and methods of career management in compliance with international CSR standards demands the integration of factors significant for Russian practice into the base models of career theory. To that end, authors expanded the classic model of Lorne Carmichael [2] and conducted empirical study of significance of factors introduced in the model.

\section{THEORETICAL FRAMEWORK}

An introduction to the analysis of new factors is based on the traditional ones for the career theory approach to studying vertical mobility. In order to estimate an interaction between internal and external mobility, it is necessary to mention several scholars. Agrawal, Knoeber and Tsoulouhas studied the way companies chose candidates for the highest position in firms, among internal and external employees [3]. According to the model presented, insiders offer an advantage in comparison with outsiders and, as these authors postulated, this obstacle stimulates the firms' personnel to work very effectively. In that context, Sicherman, Galor regard the internal promotion of workers as a company`s decision, while external promotion - as a worker`s decision [4]. Jovanovic found evidence that the major determinants of high status acquisition in corporate top-management are the education level, socio-demographic characteristics, and the work experience of candidates [5]

Sorokin, studying the career of low and middle managers, established that the internal mobility of employees is most common for the oil and gas industry. In the context of employees' age, the highest share of interfirm mobility (83.8\%) was observed in the youngest age group (22-26 years) 
[6]. That author explains such effect by the willingness of owners to appoint only well-tried employees to managerial positions. In a similar way, $27.8 \%$ of chief executives are employees holding the same position, previously, in another company, so this is a percentage of horizontal mobility. This paper also examines that a candidate, aspiring to the highest managerial positions, should possess enough work experience and several higher qualifications. In particular, such requirements determine the signal mechanisms for revealing the essential competences of the candidates.

As applied to this research, there is evidence that in old sectors of the economy, one prefers having experienced and mature top-managers in key positions; among them, the presence of women and invited foreign managers is unusual. Concerning gender peculiarities, women stay on in one position longer, they are involved in the interfirm mobility process more often. This can be explained by the presence of significant barriers for them in the internal labour market [7].

To define the determinants of career development, the authors appeal to the theoretical models of European scholars of the twentieth century, the founders of career theory.

For the first time in history, the theory of firm and agency problems was tackled by Fama [8]. He claimed that for the purpose of successful promotion, workers should seek to save their reputation, so they make maximum efforts and work effectively. His follower Holmstrom formalized this thesis, having shown that the problem of lack of information about employee's abilities at the beginning of his career could be solved by linking the firm's output and manager's contribution (the sum of abilities and efforts), and white noise (the remaining factors) [9]. In each period the firm has the possibility to observe the outputs and after a while assess the manager's efforts precisely.

The next step in the development of this firm theory was taken in the direction of human capital acquisition, where the classical authors are [10]. He postulated two types of human capital: a common one suitable for many firms and a specific one distinctive for just one firm. Both types of human capital are accumulated by workers through studying and advanced training. An optimal distribution of costs relating with the acquisition of common and specific competences, including its official certification, implies three parties: government, firm and worker. In view of that, higher level of competencies allow employees aspiring to higher salaries, so then the costs of additional education are incurred by employees themselves.

Becker, however, added that the acquisition of specific human capital could lead to indefinite consequences (for instance, worker's decision to resign). Hashimoto formalized this argument of Becker's, showing that the uncertainty of the worker's future productivity actually exists. According to his research, the costs of training and its benefits should be distributed between the firm and the worker [11].

Another approach for eliminating uncertainty was introduced by Carmichael [2]. He set up a two-period model, where the worker's productivity and job satisfaction in the second period are stochastic variables and focus attention on the advantages of a compensation scheme. Such scheme proposes that highly productive workers, by the end of their career, could be appointed on one of a few (finite number) highly-paid positions. Carmichael showed that the optimal compensation scheme of such job-type accounts for much less losses than in Becker's and Hashimoto's distribution and guarantees the greatest possible retaining of personnel, consistent with social responsibility. Summarizing all of the above-mentioned information, let us base this research on Carmichael's theoretical model (Fig.1).

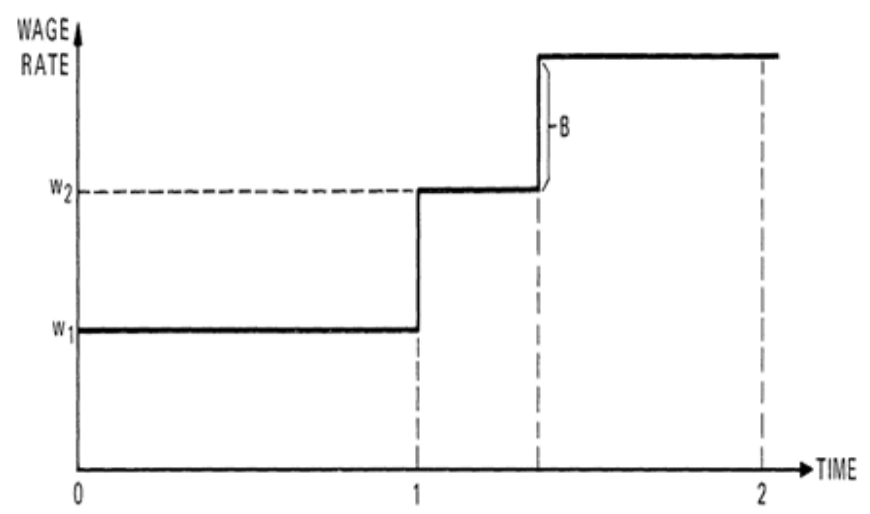

Fig. 1. Carmichael's theoretical model of wage rate.

The main implication of the model is the following: when both firms and workers invest in human capital and information about productivity, job satisfaction could not be actually changed. There is a contract established for a fixed number of highly-paid positions, which should be distributed among educated workers based on their work experience. Such contract provides effective staff rotation in the firm and meets the conditions of maximum total welfare.

This given model allows us to make an assumption about a simultaneous positive correlation between education, work experience (on-the-job training here), on the one hand, and intensity of promotion and level of salary, on the other. The basic model is extended by means of other factors having a potential impact on the building of a successful career path.

\section{RESEARCH HYPOTHESIS}

1 - Education. It is hypothesed that higher levels of education should increase the probability of inter-firm labour mobility. This proposal could be explained by the fact that a highly educated worker is likely to be promoted up the career ladder due to his applying competences accumulated during the training. According to Harry Becker's theory of human capital, labour productivity, and consequently salary, depends on the human capital of worker. Education and the acquisition of new knowledge and skills in the workplace represent investments in human capital, which in turn increase labour productivity; as a result, the employer has to pay a higher salary in order to avoid worker's switching to rival firms.

2 - Common and specific work experience. Work experience appears to be an essential factor in the process of the generating of human capital. Common work experience reflects all the acquired professional abilities and skills. The greater experience the worker has, the higher are the chances of promotion. It follows that the higher preservation of labour 
resources in the one firm that allows it to incur social obligations to the fullest extent more easily.

It is suggested that specific experience positively influences the quality and intensity of inter-firm mobility. According to job-matching theory, in the process of the increasing of specific experience, the level of information asymmetry decreases: employer reveals actual productivity of worker and employee reveals workplace characteristics such, as it was shown by prof. Flinn [12].

3 - Age. A positive correlation between age and the probability of inter-firm promotion is expected. Young workers are willing to undergo training and adapt to new conditions rapidly. In this connection, they represent personnel potential for future promotion to vacant high positions. Furthermore, in compliance with CSR standards, an employer should provide recruitment and career growth for young workers.

4 - Gender. There is a distinction in the scale and path ways of labour mobility between women and men, especially in conformity with the internal labour market. The intensity of inter-firm labour mobility is significantly higher among men, according tesis of prof. Ransom [13], so, then, to be promoted on the career ladder women should possess many more qualifications then men, as it wsa shown by Lazear and Rosen [7].

5 - Marital status. This paper proposes that presence of spouse and children negatively effects on promotion of a worker. We relate it to losses in productivity for many reasons (difficulties in staying at the office, working at weekends, or going on business trips). So, single workers are more attractive candidates for responsible positions than his colleague, a family-man.

\section{DATA}

The database at the authors' disposal represents information about the personnel at an oil and gas industry factory, consisting of cross-sectional data, with allowance for worker's promotion from the date of the factory's establishment. Data on salary and employment number (about 300 workers) is presented by an average index of 2016 .

The corporate hierarchy of internal labour market seems traditional for this sort of analysis: a pyramid with a wide base. The target group of this research, managers, includes just $5 \%$ of the total personnel. Such a structure arises naturally from the demands of industrial enterprise, an overwhelming majority of workers are employed in "blue collar" positions (Fig. 2).

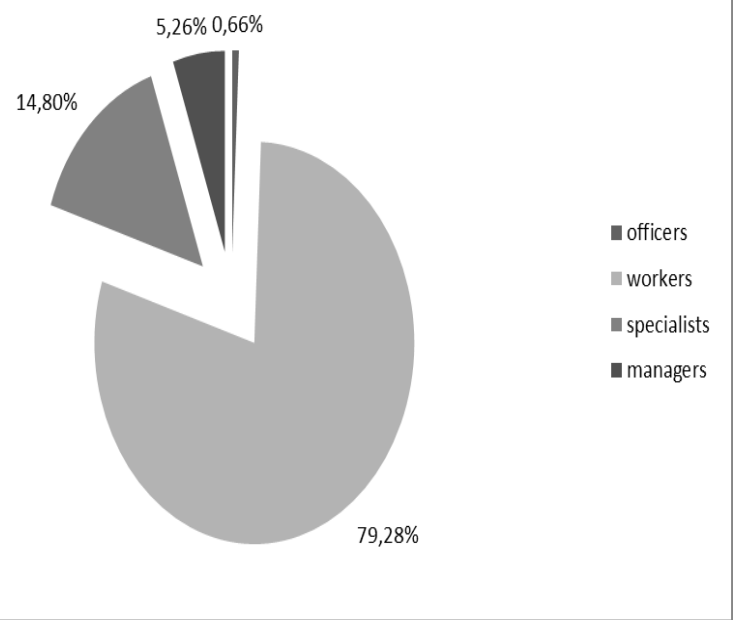

Fig. 2. Personnel structure.

The percentage of promoted managers is $37.5 \%$, whereas just $26.7 \%$ of specialists were appointed to their positions through inter-firm mobility mechanisms. This indicates the existence of significant external hiring for key positions (Fig. 3).

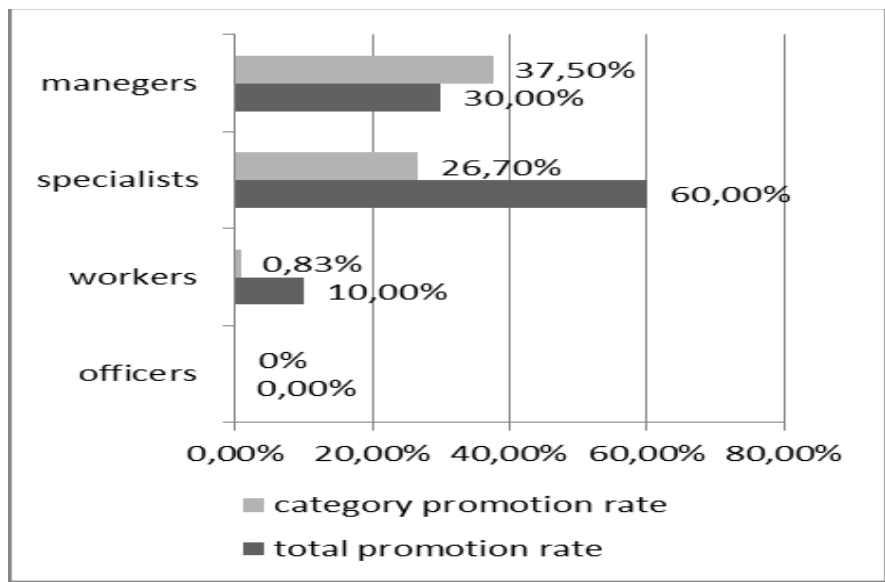

Fig. 3. The percentage of promoted managers, officers, workers and specialists.

Based on the collected data, the authors could calculate that, on average, managers get higher wages than other work groups, then specialists follow; and after them - manual workers. Some unexpected figures, however, are observed; for instance, maximum wages of manual workers exceed those for specialists; also, the minimum salaries for managers are comparably less than the average wages of manual workers. This type of distribution reflects a significant heterogeneity of the position in each work group (Fig. 4). 


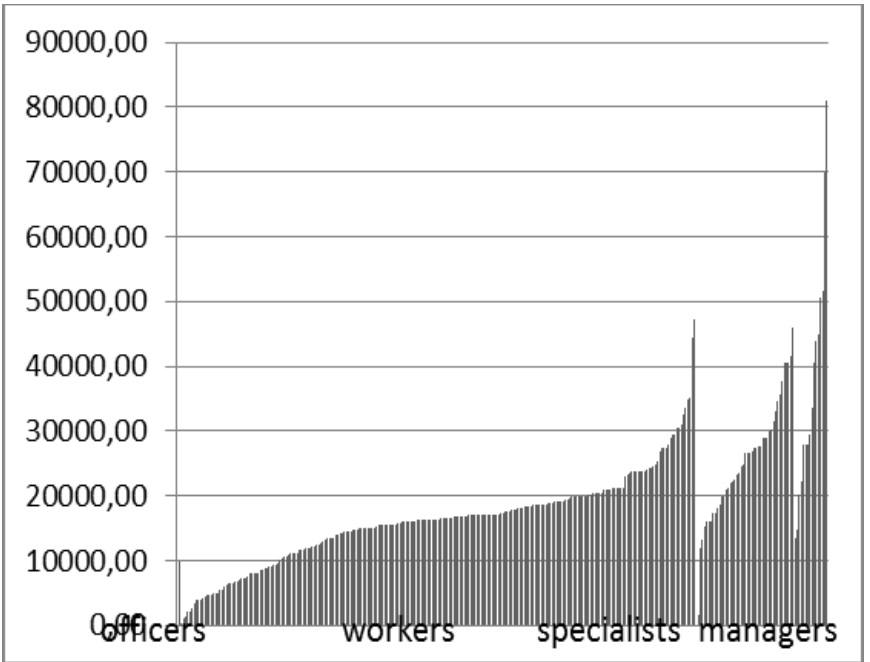

Fig. 4. Wage difference, RR.

At this stage of the research, it is possible to conclude that workers holding higher positions in the corporate hierarchy earn more, on average. In this connection, there is a differentiation of salaries in "white-collar" and "blue-collar" positions, where the lowest wages belong to services and unqualified manual workers, respectively.

\section{Methodology}

For a more complete and credible analysis of factors having an influence on manager's career path let us introduce three models with dependent variables: promotion number, salary and having a relative position in the executive office. The most convenient method of analysis is the application of OLS regression: by this means, the first two models are tested. The position criteria are studied using probit-regression. Examination for compliance with Gauss-Markov theorem, absence of heteroscedasticity and multicollinearity give positive results, so one could contend that the given linear type of regression function produces the finest estimated coefficients.

\section{A. Model 1. Promotions}

The first model is specified as follows:

$$
\operatorname{Prom}_{i}=\alpha+\beta x_{i}+\gamma_{1} \operatorname{man}_{i}+\gamma_{2} \operatorname{spec}_{i}+\gamma_{3} \operatorname{serv}_{i}+\varepsilon_{i},
$$

Here, $\operatorname{Prom}_{i}$ is the dependent variable representing the number of facts of vertical mobility for the analyzed period. $x_{i}$ is a vector of control variables including worker's social and demographic characteristics such as age, gender, marital status, the number of children under 15, the level of education, experience and salary. $\operatorname{man}_{i}, \operatorname{spec}_{i}, \operatorname{ser}_{i}$ are dummy variables referring to membership of a certain work group, where, for avoidance of the collinearity problem, one assesses the largest work group as a base: manual workers.

\section{B. Model 2. Salary}

In order to estimate the effect of personnel characteristics on salary, the authors formulated a regression of Mincer's type, adding a dummy charging of the work group indicator.

$$
\operatorname{Sal}_{i}=\alpha+\beta x_{i}+\gamma_{1} \operatorname{man}_{i}+\gamma_{2} \operatorname{spec}_{i}+\gamma_{3} \operatorname{serv}_{i}+\varepsilon_{i},
$$

where $S a l_{i}$ measures earnings of the worker for a representative period; $x_{i}$, as in the previous model, is a vector of individual characteristics of the employee with one exception: instead of salary, it includes a promotion variable.

\section{Model 3. Managerial position}

$$
\operatorname{Man}_{i}=\alpha+\beta x_{i}+\varepsilon_{i},
$$

$M a n_{i}$ is coded 1 if the worker has the status of manager; and 0 otherwise. Factor $x_{i}$ includes a salary indicator but does not have an education variable because it is collinear with key variable. It means that every manager of the given company has a higher qualification.

\section{RESULTS}

The observed regression results allow us to confirm, partly, the hypotheses proposed in previous sections.

\section{A. Education}

According to the postulates of human capital theory, there is a positive interrelation between the productivity of a worker and the level of one's education. Hence, there arises the idea of the promotion of the most productive or, which is practically the same, the most educated worker. Solely for this reason, the authors observe that every manager has a higher qualification.

However, one's education level does not seriously affect promotion and salary. Possible reason could stem from the fact that the role of one's general education becomes imperceptible compared with the development of specific professional skills for a certain workplace. Most often on-thejob training takes place in an informal way: through accumulation of experience during the tutorship and operation in the related environment.

\section{B. Work experience}

In the body of this report, the evidence that substantial specific work experience helps worker to be more eligible for promotion, and hence positively results in increased salary, has been found. Moreover, workers from the managers and specialists work groups have the highest probability of being promoted. This situation could be considered as a signal that such employees are of extrinsic value for a given work environment due to their accumulated firm-specific human capital.

\section{Age}

The results of research testing show that in the given firm, despite its belonging to the oil and gas industry, any age dependence is absent; in other words, to be promoted or appointed to managerial positions, a person does not have to reach any certain age. The age-grouping variable has an impact only on the salary of managers and specialists

\section{Gender}

The proportion of women in the group of office and management personnel approaches $44 \%$ whereas in the whole company, this share is $18 \%$. This testifies as to the absence of the "glass ceiling" effect among the top steps of the career ladder, a common obstacle in career progression for women. It 
should be noted also that women are appointed to higher positions through the mechanism of external hiring, because there was no observation of women being promoted internally.

\section{Marital status}

The factor of "spouse presence" is an influence at the $5 \%$ significance level in the promotion of manual workers by the skill category. This is, possibly, because spouses simplify housekeeping for men, the majority of representatives in this work group. This spouse factor is also significant at the $10 \%$ for specialists. The above-mentioned result allows us to suggest that these two categories of personnel are more in need of family support in comparison to managers and services. Married women, as it was revealed, earn significantly more than their single colleagues. This could be explained by their higher productivity in view of their partly imposing household chores on husbands and better psychological background. The number of small children has no noticeable impact on these key indicators of research.

\section{CONCLUSION}

The authors can claim with a high degree of confidence that these given empirical results are consistent with the theses of the theoretical model and serve as proof of them and they also reflect the specific value of keeping the CSR norms in Russian companies within the oil and gas industry [14].

The authors see the main barrier for verification of the theoretical hypotheses, connected with the peculiarities of inter-firm labour mobility, in a scarcity of empirical material. It is extremely difficult to get access to mass data about employees: their career length in the firm, their real salaries, and to take into account unobserved individual characteristics. Nevertheless, there is a strong interest in inter-firm processes in respect of the formation of career paths and workers' compensations and this paper aims to shed light on one side of the functioning of the internal labour market. This means to reveal the interrelation between the individual characteristics of workers and the probability of their promotions to higher positions in the corporate hierarchy; their earning of salary bonus and all other aspects which characterize the level of corporate responsibility to the wider society.

\section{References}

[1] A. Kokovikhin, N. Sharapova, I. Borisov, "National system of certification of worker's competence and qualification as the institute of labour market," In 10th international days of statistics and economics, Prague, pp. 871-881, 2016.

[2] H. Carmichael, Lorne. "Firm-Specific Capital and Promotion Ladders", Bell Journal of Economics, 14(1), pp. 251-58, Spring 1983.

[3] T. Tsoulouhas, C. R. Knoeber, A.Agrawal, "Contests to become CEO: incentives, selection and handicaps". Economic Theory, 30(2), pp. 195221, 2007.

[4] N. Sicherman, O. Galor, "A Theory of Career Mobility", Journal of Political Economy, 98(1), pp. 169-192, 1990.

[5] B. Jovanovic, "Firm-specific Capital and Turnover". Journal of Political Economy, 87(6), pp. 1246-1260, 1979.

[6] P. Sorokin, Career of low and mid-level managers of Russian business organizations as a social phenomenon: Abstract of dissertation for the degree of candidate of sociological sciences, Moskow, 2013.

[7] Lazear, E. P., Rosen, S. "Male-Female Wage Differentials in Job Ladders", Journal of Labor Economics, 1990, 8(1), S106-S123.

[8] E. F. Fama, "Agency Problems and the Theory of the Firm", The Journal of Political Economy, Vol. 88, No. 2, pp. 288-307, Apr., 1980.

[9] B. Holmstrom, "Moral Hazard in Teams", The Bell Journal of Economics, 13(2), pp. 324-340, 1982

[10] G. Becker, "Investment in Human Capital: A Theoretical Analysis", Journal of Political Economy, vol. 70, pp. 9-49, 1962.

[11] Hashimoto, M."Firm-Specific Human Capital as a Shared Investment". The American Economic Review, 1981, 71(3), pp. 475-482.

[12] C. J. Flinn, "Wages and Job Mobility of Young Workers", Journal of Political Economy, 94(3), pp. 88-110, 1986.

[13] M. Ransom, R. L. Oaxaca, Intrafirm Mobility and Sex Differences in Pay", Industrial and Labor Relations Review, 58(2), pp. 219-237, 2005.

[14] A. Kokovikhin, E. Ogorodnikova, D. Williams, A. Plakhin, Institutional Factors in the Evaluation by the Entrepreneur of Municipality Investment Climate. Economy of region, Vol. 1(1), pp. 80-92, 2017. 